\title{
Learning from Early Adopters of Blockchain Technology: A Systematic Review of Supply Chain Case Studies
}

\author{
Sevda Dede, Mesut Can Köseoğlu, H. Funda Yercan
}

\author{
"We are not fit to lead an army on the march unless we are familiar with the face of the \\ country - its mountains and forests, its pitfalls and precipices, its marshes and swamps. " \\ Sun Tzu \\ The Art of War
}

\begin{abstract}
Blockchain technology is widely seen as a promising technology for global supply chains, though early adoption of the technology is both costly and risky. Along with many other discouraging factors, large investments required to enter or develop a blockchain raise barriers to entry. Concerns about potential benefits, on the other hand, have led to companies questioning whether it is worth it. Consequently, many players in the global arena are still preferring to wait by observing current practices before making investments, while trying to figure out what the technology might bring them. Hence, the main purpose of this paper is to research various implementations of blockchain technology in supply chains, in order to learn from its early adopters. For this purpose, we chose case studies as the research method, which we used in a systematic way. We focused on multiple relevant case studies from previous research concerning the use of blockchain technology in supply chain practices. Through a systematic analysis of case studies, the paper aims at bringing forward different views, approaches, and results about blockchain adoption, as a way to show the pros and cons of adopting the technology under certain circumstances. The research was obtained from the Web of Science Core Collection. This paper contributes to the literature by showcasing the use of blockchain in supply chains via multiple cases to learn from early blockchain adopters in supply chain practices.
\end{abstract}

\section{Introduction}

Blockchain technology is expected to contribute to the global economy in many ways. A recent study by PwC (2020) estimates that blockchain technology has the potential to boost the global GDP by $\$ 1.76$ (USD) trillion by 2030 through five main areas. The following table summarizes the report's findings from the report $(\mathrm{PwC}$, 2020), showing the top five uses that are driveing blockchain adoption and their estimated economic contributions to the global GDP by 2030 .
As the emphasis on provenance (that is, verifying the sources of goods, tracking their movement, and increasing transparency) demonstrates, a key area of blockchain applications is global supply chains. Some reasons that make supply chains a potentially high-gain area for blockchain implementation include their complex network structure with several stakeholders, need for information sharing between the parties, difficulty and risk in transfer of documents, timeconsuming processes, and lack of trust between parties. Research shows that the number of blockchain

Table 1. Top five uses driving blockchain adoption and their estimated economic contribution to GDP

\begin{tabular}{|l|l|}
\hline \multicolumn{1}{|c|}{ Uses driving blockchain adoption } & \multicolumn{1}{c|}{ Potential boost to global GDP by 2030 } \\
\hline Provenance & $\$ 962 \mathrm{bn}$ \\
Payments and financial instruments & $\$ 433 \mathrm{bn}$ \\
Identity & $\$ 224 \mathrm{bn}$ \\
Contracts and dispute resolution & $\$ 73 \mathrm{bn}$ \\
Customer engagement & $\$ 54 \mathrm{bn}$ \\
\hline
\end{tabular}




\section{Learning from Early Adopters of Blockchain Technology: A Systematic Review of Supply Chain Case Studies}

\section{Sevda Dede, Mesut Can Köseoğlu, H. Funda Yercan}

engagements per industry is highest in the supply chain industry, constituting $19 \%$ of all distributed ledger technology (DLT) implementations worldwide (HFS Research, 2020). Yet, the number and variety of use cases is still limited, while much potential remains to be realized.

\subsection{Purpose and structure of the paper}

This study aims to research and evaluate various implementations of blockchain and DLT in supply chains in order to provide insights regarding applications currently trending, while also establishing a viable resource to learn from case studies in the related literature. Conforming with this purpose, the study is designed as a systematic literature review of formerly conducted case studies concerning the use of blockchain technology in supply chain practices.

The study has five main sections. The introductory section specifies the scope and structure of the paper, provides a general overview related to the digital economy, and focuses on blockchain implementation in supply chains, setting forth problems in supply chains that the use of blockchain could solve. The second section describes the research methodology, namely research questions addressed in this study, the search process, inclusion and exclusion criteria for the cases, and data collection and analysis procedures. The third section presents the actual case studies used, while the fourth section details the results associated with each research question, along with limitations of the study. Finally, the conclusion draws an application from the search results and findings, while shedding light on future research possibilities.

\subsection{Blockchain Implementations in Supply Chains}

As challenges and environmental conditions (that is, complexity, intense competition, pressure on lead times, regulations, etc.) push organizations to find novel solutions, many global enterprises are placing emphasis on understanding how blockcain technology can help improve their supply chain operations to reach strategic objectives. Gradually enabled in global supply chains over the years, blockchain technology has a goal of improving efficiency through digitalization. Benefits from blockchain implementation in supply chains include keeping track of cargoes, enchanced visibility, decreased time spent in customs clearance, reduced risk, cost efficiency, and reduction in paperwork (Aich et al., 2019). According to an analysis by the platform
Blockdata, six of the companies on Forbes' "Blockchain 50 " list (of the largest global brands with an annual revenue of over $\$ 1$ billion) developed blockchain use cases directly related to supply chain management (Kshetri, 2021). Among these 50, 15 companies, including IBM, Nestlé, Walmart, and Amazon, have used blockchain technology for traceability/provenance purposes, highly related to supply chain management, with one third of these projects in the pilot phase, and the rest already in use.

The beneficial features of distributed ledger technology have opened up many possiblities for improving supply chains. With high trade volumes and a large number of players, the shipping industry is an important component of supply chains worldwide, providing a number of very good examples of blockchain implementation. Maersk and International Business Machines (IBM), for example, have been collaborating for ecosystem-wide blockchain integration in maritime transportation, starting the "TradeLens" project in 2018. The maritime transportation domain constitutes an information structure, when considered as a domain consisting of many actors scattered in a complex supply chain environment, with direct or indirect collaboration (Stopford, 2009). Mike White, Head of TradeLens at Maersk, stated (2019) that in the shipping industry, data gets trapped in organizational silos, operations are complex and costly, processes are time-consuming, clearance can be subject to delays, and collaboration with stakeholders in the industry's external environment is a necessity. Hence, the TradeLens initiative aims to increase transparency and traceability, while eliminating intermediaries and paperwork required for maritime transportation. The platform was designed with accessibility in mind, providing transparency and traceability to shipowners, brokers, customs, port authorities, and insurance companies by tracking cargo for all users in the private blockchain network, from the first port of call to the last.

According to the 2020 Maersk Sustainability Report (2021), TradeLens integration has increased to over 220 organizations, comprising data from more than ten ocean carriers, and 600 ports and terminals, thus covering almost half the world's ocean container cargo. TradeLens will be utilized for developing countries in automation of sea cargo data in a multi-stakeholder project starting from Sri Lanka and Cambodia (Maersk, 2021). 


\title{
Learning from Early Adopters of Blockchain Technology: A Systematic Review of Supply Chain Case Studies
}

\author{
Sevda Dede, Mesut Can Köseoğlu, H. Funda Yercan
}

\section{Research Method}

This study was designed as a systematic review of case studies that rigorously reviews several formerly conducted case studies. Through a systematic analysis of these case studies, our study aims at presenting different views, approaches, and results in relation to blockchain implementation in supply chains, thus giving readers a chance to grasp the pros and cons of adopting the technology under certain conditions.

In carrying out the systematic review, this study follows guidelines as proposed by Kitchenham (2004) who described a systematic review as "a means of identifying, evaluating and interpreting all available research relevant to a particular research question, or topic area, or phenoenon of interest". Systematic reviews require a well-defined methodology in order to decrease the probability of being biased in examining the related literature. Further, the methodology should be made transparent to readers through detailed explanation and documentation about the search process (Kitchenham, 2004). To this end, the research questions addressed in this study, search process, inclusion and exclusion criteria for the cases, procedures for data collection, and analysis are explained in detail.

\subsection{Research Questions}

This study aims to answer the following research questions (RQ):

\section{RQ1: What blockchain features regarding blockchain implementation in supply chains are addressed in case studies?}

RQ2: Which sectors are leading case study research on blockchain implementation in supply chains?

RQ3: What benefits of adopting blockchain technology are improving supply chain operations and helping to achieve supply chain strategies?

\section{RQ4: What are the biggest challenges of adopting blockchain technology in supply chains?}

RQ1 intends to analyse blockchain features that are most utilized and, thus, most emphasized, in supply chain case studies. RQ1 provides insight into the needs of supply chains regarding implementation of blockchain technology in currently utilized systems, while emphasizing where most problems in supply chains occur. In RQ2, the analysis of blockchain adoption from a sectoral perspective shows information on sectors that have most utilized blockchain in their supply chains, as well as those needing more research on blockchain adoption. Finally, RQ3 and RQ4 provide analysis regarding advantages and drawbacks, respectively, of blockchain adoption.

\subsection{Search Process}

The search process of this study was performed electronically using the Web of Science (WoS) database. The cases were obtained from the WoS Core Collection, starting with a broad search with the terms "blockchain" and "distributed ledger" (or DLT) in the title, along with the terms "case study" and "supply chain" in the abstract $[\mathrm{TI}=$ (blockchain OR "distributed ledger" OR $\mathrm{DLT}$ ) and $\mathrm{AB}=$ ("case study" AND "supply chain")]. Although this paper considers blockchain technology, the researchers consciously did not limit the search terms to "blockchain". On account of the fact that blockchain is a type of distributed ledger technology (DLT), and that both are commonly used interchangeably, the search terms included "distributed ledger" and "DLT", as well. This approach eliminated the risk of missing out on a relevant work simply because it used the term "distributed ledger" instead of "blockchain". Given that not all distrubuted ledgers are blockchains, but that all blockchains are fundamentally distributed ledgers, the main research subject in this study covers a set of case studies on blockchain applications in supply chains.

Because a number of papers phrased the blockchain concept as "block-chain" or "block chain", the initial database search included the terms "block-chain" and "block chain," along with the most commonly used term, "blockchain". Adding them to the database search, however, did not bring up any further relevant results, and thus, the two less common variations of the keyword "blockchain" (that is, "block-chain" and "block chain") were excluded from the search. To direct the search toward a focus on maritime supply chains, the search terms "shipping" and "maritime" were added to the initial search term, "supply chain".

As a default search parameter, we set the timespan for our research from January 1st, 2017 to April 15th, 2021. The initial search with the aforementioned combinations identified 171 results in total, 125 of which were articles published in journals. The remaining 46 search results consisted of 37 conference papers 


\section{Learning from Early Adopters of Blockchain Technology: A Systematic Review of Supply Chain Case Studies}

\section{Sevda Dede, Mesut Can Köseoğlu, H. Funda Yercan}

(proceeding books included), and 9 books or chapters in a book. For the second step, any duplicates were identified and removed, after which the abstracts were scanned for relevance, and non-relevant papers were also eliminated. The remaining 63 papers were those included in our systematic analysis of case studies.

\subsection{Inclusion and Exclusion Criteria}

In order to focus the research on case studies that have dealt with blockchain implementation in supply chains, certain papers were excluded from the initial list of results. The exclusion was carried out according to the following criteria:

- Conjectural case studies (case studies that included hypothetical applications)

- Non-relevant case studies (case studies that did not include a supply chain application)

- Technical case studies (case studies that focused mainly on software, but did not include a supply chain application)

Furthermore, certain inclusion criteria were set as:

- Case studies that included real supply chain systems, but only simulated blockchain implementations
- Mathematical approaches that provided supply chain case studies

\section{Results}

The following table presents the 63 selected case studies relevant to our systematic literature review, along with a summary of each study.

We assigned each case study an identification number in the table (for example, CS1, CS2). In the year of publication column, "EA" in parentheses denotes the publication as an early access publication. Under the type of publication column, journals are indicated by a "J", books by a "B", and conference papers by a "C".

\section{Discussion}

This section systematically presents answers to our research questions, discussing what may be learned from the literature on blockchain in supply chains.

\subsection{What blockchain features regarding blockchain implementation in supply chains are addressed in case studies?}

The systematic review demonstrates that a number of blockchain features are specifically addressed in supply chain case studies. Traceability (that is, the ability to track goods), for instance, is addressed in 55 of the 63 case studies reviewed. Traceability, combined with

Table 2. Systematic literature review of case studies

\begin{tabular}{|l|l|l|l|l|l|}
\hline CS ID & Author(s) & Year & Main topic & $\begin{array}{l}\text { Type of } \\
\text { Publcation }\end{array}$ & $\begin{array}{l}\text { No of } \\
\text { Citations }\end{array}$ \\
\hline CS1 & Alles \& Gray & 2020 & Pharmaceutical & J & 7 \\
CS2 & Bal \& Pawlicka & 2021 & Retail, Finance & $\mathrm{J}$ & - \\
CS3 & Baralla et al. & 2021 & Food SC & $\mathrm{J}$ & 6 \\
CS4 & Bodkhe et al. & $2020($ EA) & Food SC, Cyber security & $\mathrm{J}$ & 9 \\
CS5 & Caldarelli et al. & 2020 & Food SC & $\mathrm{J}$ & 9 \\
CS6 & Casino et al. & 2020 (EA) & Food SC & $\mathrm{J}$ & 7 \\
CS7 & Curbera et al. & 2019 & Healthcare & $\mathrm{J}$ & 7 \\
CS8 & Danese et al. & 2021 & Food SC & $\mathrm{J}$ & - \\
CS9 & Ethirajan et al. & 2020 & Manufacturing & $\mathrm{J}$ & - \\
CS10 & Fu et al. & 2020 & Food SC & $\mathrm{J}$ & 4 \\
CS11 & Garrard \& Fielke & 2020 & Food SC & $\mathrm{J}$ & 7 \\
CS12 & Gausdal et al. & 2018 & Maritime & $\mathrm{J}$ & 60 \\
CS13 & Khatoon et al. & 2019 & Green operations & $\mathrm{J}$ & 28 \\
CS14 & Kshetri & 2018 & Shipping, Food SC, Military, & $\mathrm{J}$ & 688 \\
& & & Pharmaceutical, Retail, Insurance & &
\end{tabular}




\section{Learning from Early Adopters of Blockchain Technology: A Systematic Review of Supply Chain Case Studies}

Sevda Dede, Mesut Can Köseoğlu, H. Funda Yercan

Table 2. Systematic literature review of case studies (cont'd)

\begin{tabular}{|c|c|c|c|c|c|}
\hline $\operatorname{CS} 15$ & Kumar et al. & 2020 (EA) & Logistics & $\mathrm{J}$ & - \\
\hline $\operatorname{cs} 16$ & Kumar et al. & 2020 (EA) & Logistics & $\mathrm{J}$ & 4 \\
\hline CS17 & Li \& Zhou & 2020 (EA) & $\begin{array}{l}\text { Maritime, Food SC, Logistics, } \\
\text { Green Operations }\end{array}$ & $\mathrm{J}$ & 2 \\
\hline $\operatorname{CS} 18$ & Li et al. & 2020 & Retail & $\mathrm{J}$ & 14 \\
\hline $\operatorname{CS} 19$ & Maity et al. & 2021 & Food SC & $\mathrm{J}$ & 1 \\
\hline $\operatorname{CS} 20$ & Orjuela et al. & 2021 & Food SC & $\mathrm{J}$ & - \\
\hline $\operatorname{CS} 21$ & Park \& Li & 2021 & Food SC, Maritime & $\mathrm{J}$ & - \\
\hline $\operatorname{CS} 22$ & $\begin{array}{l}\text { Patelli \& } \\
\text { Mandrioli }\end{array}$ & 2020 & Food SC & $\mathrm{J}$ & 7 \\
\hline $\operatorname{CS} 23$ & Perez et al. & 2020 & Textile & $\mathrm{J}$ & 7 \\
\hline $\mathrm{CS} 24$ & Philipp & 2020 & Maritime, Green Opeartions & $\mathrm{J}$ & 2 \\
\hline $\mathrm{CS} 25$ & Philipp et al. & 2019 & Maritime & $\mathrm{J}$ & 18 \\
\hline $\operatorname{CS} 26$ & Prause & 2019 & Logistics, Autonomous Delivery & $\mathrm{J}$ & 10 \\
\hline $\operatorname{CS} 27$ & Prause \& Boevsky & 2019 & $\begin{array}{l}\text { Small and medium enterprises } \\
\text { (SME), Food SC, Autonomous } \\
\text { Delivery }\end{array}$ & $\mathrm{J}$ & 8 \\
\hline $\operatorname{CS} 28$ & Rijanto, Arief & 2020 (EA) & Food SC & $\mathrm{J}$ & - \\
\hline $\operatorname{CS} 29$ & $\begin{array}{l}\text { Rodriguez- } \\
\text { Espindola et al. }\end{array}$ & 2020 & Humanitarian & $\mathrm{J}$ & 13 \\
\hline $\operatorname{CS} 30$ & Roeck et al. & 2020 & $\begin{array}{l}\text { Diamond, Food SC, } \\
\text { Pharmaceutical }\end{array}$ & $\mathrm{J}$ & 31 \\
\hline CS31 & Rogerson \& Parry & 2020 & Food SC & $\mathrm{J}$ & 25 \\
\hline $\mathrm{CS} 32$ & Shemov et al. & 2020 & Construction & $\mathrm{J}$ & 1 \\
\hline $\operatorname{CS} 33$ & Sivula et al. & 2021 & $\begin{array}{l}\text { Construction, Regional } \\
\text { Development }\end{array}$ & $\mathrm{J}$ & - \\
\hline CS34 & Sternberg et al. & 2021 & Food SC & $\mathrm{J}$ & 17 \\
\hline $\operatorname{cs} 35$ & Stranieri et al. & 2021 & Food SC & $\mathrm{J}$ & 11 \\
\hline $\operatorname{CS} 36$ & Sund et al. & 2020 & Retail & $\mathrm{J}$ & 8 \\
\hline $\operatorname{CS} 37$ & $\begin{array}{l}\text { Tan \& } \\
\text { Sundarakani }\end{array}$ & 2021 & Logistics & $\mathrm{J}$ & 2 \\
\hline $\operatorname{CS} 38$ & $\begin{array}{l}\text { Toennissen \& } \\
\text { Teuteberg }\end{array}$ & 2020 & $\begin{array}{l}\text { Shipping, Food SC, Retail, } \\
\text { Pharmaceutical, Diamond }\end{array}$ & $\mathrm{J}$ & 78 \\
\hline $\operatorname{CS} 39$ & Tseng \& Shang & 2021 & $\begin{array}{l}\text { Healthcare, Accounting, Food SC, } \\
\text { Logistics }\end{array}$ & $\mathrm{J}$ & - \\
\hline $\operatorname{CS} 40$ & van Hoek & 2020 & Retail, Logistics & $\mathrm{J}$ & 16 \\
\hline CS41 & Vishnubhotla et al. & 2020 & Oil Trade & $\mathrm{J}$ & 1 \\
\hline $\mathrm{CS} 42$ & Vivaldini & 2021 (EA) & Food SC & $\mathrm{J}$ & - \\
\hline $\mathrm{CS} 43$ & Wamba et al. & 2020 & Food SC, Consumer Engagement & $\mathrm{J}$ & 58 \\
\hline CS44 & Wang & 2019 & Construction & $\mathrm{J}$ & 5 \\
\hline $\operatorname{CS} 45$ & Wang et al. & 2020 & Construction & $\mathrm{J}$ & 43 \\
\hline $\operatorname{CS} 46$ & Zhou et al. & 2020 & Maritime & $\mathrm{J}$ & 5 \\
\hline CS47 & Calle et al. & 2019 & SME, Finance, Logistics & B & - \\
\hline CS48 & Di Ciccio et al. & 2018 & Pharmaceutical & B & 35 \\
\hline $\operatorname{CS} 49$ & Potancok et al. & 2020 & Pharmaceutical & B & - \\
\hline $\operatorname{CS} 50$ & Aich et al. & 2019 & $\begin{array}{l}\text { Automotive, Food SC, Retail, } \\
\text { Pharmaceutical }\end{array}$ & $\mathrm{C}$ & 32 \\
\hline $\operatorname{CS} 51$ & Casado-Vara et al. & 2018 & Food SC & $\mathrm{C}$ & 222 \\
\hline $\operatorname{CS} 52$ & Cui et al. & 2019 & Food SC & $\mathrm{C}$ & 1 \\
\hline $\operatorname{CS} 53$ & Grest et al. & 2019 & Pharmaceutical & $\mathrm{C}$ & - \\
\hline $\operatorname{CS} 54$ & Hafizon et al. & 2019 & Maritime & $\mathrm{C}$ & 4 \\
\hline $\operatorname{CS} 55$ & Haroon et al. & 2019 & Food SC & $\mathrm{C}$ & 6 \\
\hline
\end{tabular}




\title{
Learning from Early Adopters of Blockchain Technology: A Systematic Review of Supply Chain Case Studies
}

\author{
Sevda Dede, Mesut Can Köseoğlu, H. Funda Yercan
}

Table 2. Systematic literature review of case studies (cont'd)

\begin{tabular}{|llllll|} 
CS56 & Kanak et al. & 2019 & $\begin{array}{l}\text { Automative, Inner City } \\
\text { Transportation, Cyber Security, }\end{array}$ & C & 2 \\
CS57 & Koirala et al. & 2019 & $\begin{array}{l}\text { Green Opeartions } \\
\text { Reverse Auction Supply Chain }\end{array}$ & C & 2 \\
CS58 & Lam \& Lei & 2019 & Textile, Green Opeartions & C & 4 \\
CS59 & Miehle et al. & 2019 & Automotive & C & 9 \\
CS60 & Pundir et al. & 2019 & Retail & C & 19 \\
CS61 & Scheid et al. & 2019 & Cold Chain Supply Chain & C & 12 \\
CS62 & Wu et al. & 2019 & Food SC & C & 17 \\
CS63 & Yusuf et al. & 2019 & Food SC & C & 5 \\
\hline
\end{tabular}

transparency, increases supply chain visibility, while ensuring product quality and safety, thus contributing to profitability. By accessing data records with time stamps, stakeholders can track transactions in an efficient manner. Similarly, transparency provides stakeholders with the ability to monitor and access data on the chain, as addressed in 53 studies. By providing access to the history of activities, transparency also facilitates validating and auditing distributed ledger elements.

Immutability, which involves disabling the ability to make changes to initial or previous data, is another feature commonly addressed in supply chain case studies. This feature is enabled by cryptographic security in distributed ledgers and is considered as the most expensive aspect of blockchains, since it has technological requirements such as databases, distribution, and hashing to ensure the data does not change.

Security, efficiency, and confidentiality are also among the blockchain features addressed in supply chain case studies. Security refers to cybersecurity measures that prevent forced or unintentional data access by unwanted parties. The high level of difficulty in changing data on blockchains is essential regarding supply chain processes. Efficiency refers to the reduction in cost, paperwork, and unnecessary intermediaries. Faster data handling, easier accessibility, and the elimination of geographical limitations further boosts efficiency in supply chain processes. Confidentiality, meanwhile, refers to maintaining the privacy of users and their data, as well as certain aspects of their transactions. This feature is hard to balance with transparency and traceability for supply chain processes, but in blockchains, stakeholders may prefer a private permissioned blockchain option to limit the monitoring and controlling actions in the blockchain.
Finally, the culmination of all the aforementioned features of blockchain use in supply chains is trust. Trust is established by blockchain's ability to remove untrusted parties while providing information sharing, immutability, visibility, and automation. In conventional companies, stakeholder trust develops through transactions themselves, while in blockchain implemented supply chains, trust is established through blockchain distributed ledger accounting. In an environment lacking trust, blockchains carry the potential to fundamentally improve transactions between parties.

\subsection{Which sectors are leading case study research on blockchain implementation in supply chains?}

Overall, the case studies regarding blockchain implementation in supply chains are dominated by food supply chains. The number of case studies in food supply chains increased substantially in 2020 and 2021, making up 28 of the total case studies examined. Logistics, pharmaceuticals, and retail (for example, Walmart) industries are the next common areas of investigation, but still far behind food supply chains with 10,8 , and 8 cases, respectively. Finally, automotive, maritime, construction, and green operations are found to be the other significant areas for case studies.

\subsection{What are the benefits of adopting blockchain technology that are improving supply chain operations and helping to achieve supply chain strategies?}

In the case studies reviewed, the benefits of adopting blockchain technology mostly refer to features. One common advantage mentioned in the case studies is the feature of secure, real-time data handling with monitoring and controlling of data in a virtual environment. Reduced (or eliminated) paperwork in supply chain processes increases efficiency through decreased response times. Similarly, traceability 


\section{Learning from Early Adopters of Blockchain Technology: A Systematic Review of Supply Chain Case Studies}

\section{Sevda Dede, Mesut Can Köseoğlu, H. Funda Yercan}

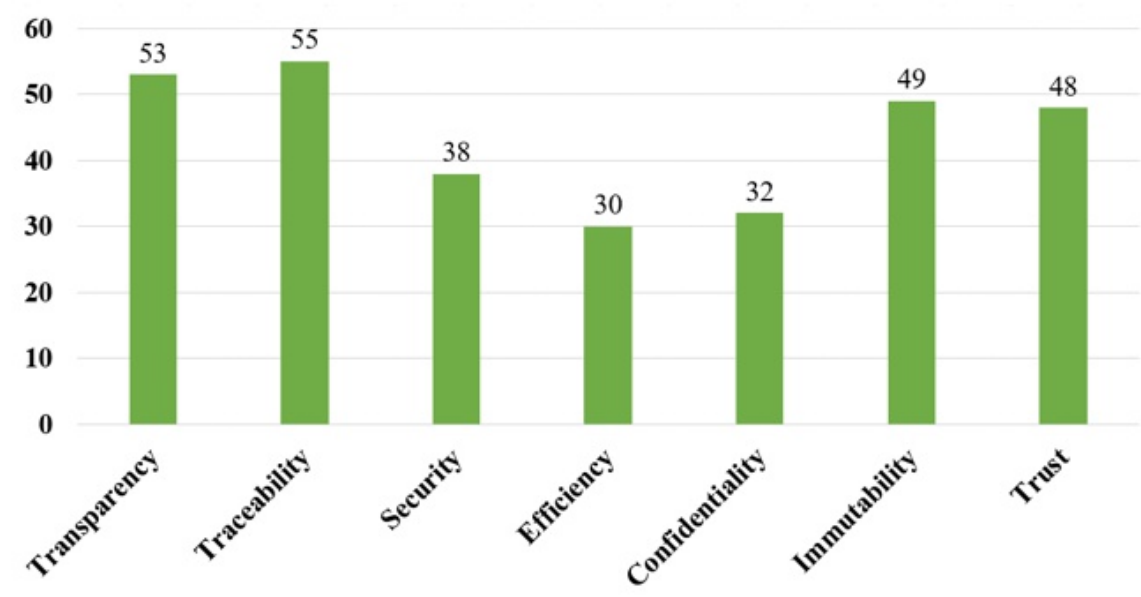

Figure 1. Blockchain features addressed in case studies

increases or goes hand-in-hand with supply chain visibility. Digitalizing the processes also reduces risk of error while removing geographic boundaries and providing easier access from all over the world.

Blockchain technology also enables flexibility in supply chains. Since data is transferred in an automated environment with digital interfaces, instead of through constant physical document exchange with couriers, the data record stored in the blockchain ledger can be available anytime. Data transparency contributes to data accessibility and information sharing among stakeholders, thereby increasing and enabling improved communications. Blockchain systems likewise facilitate interoperability in a way that aims to connect the participants of the ecosystem, while providing secure data exchange and confidentiality through decentralization and data encryption. Since complete transparency may not be desirable for some (or many) transactions in a distributed ledger ecosystem, a private permissioned blockchain option, or cases of semitransparency for certain parties in a supply chain, may be the appropriate choice.

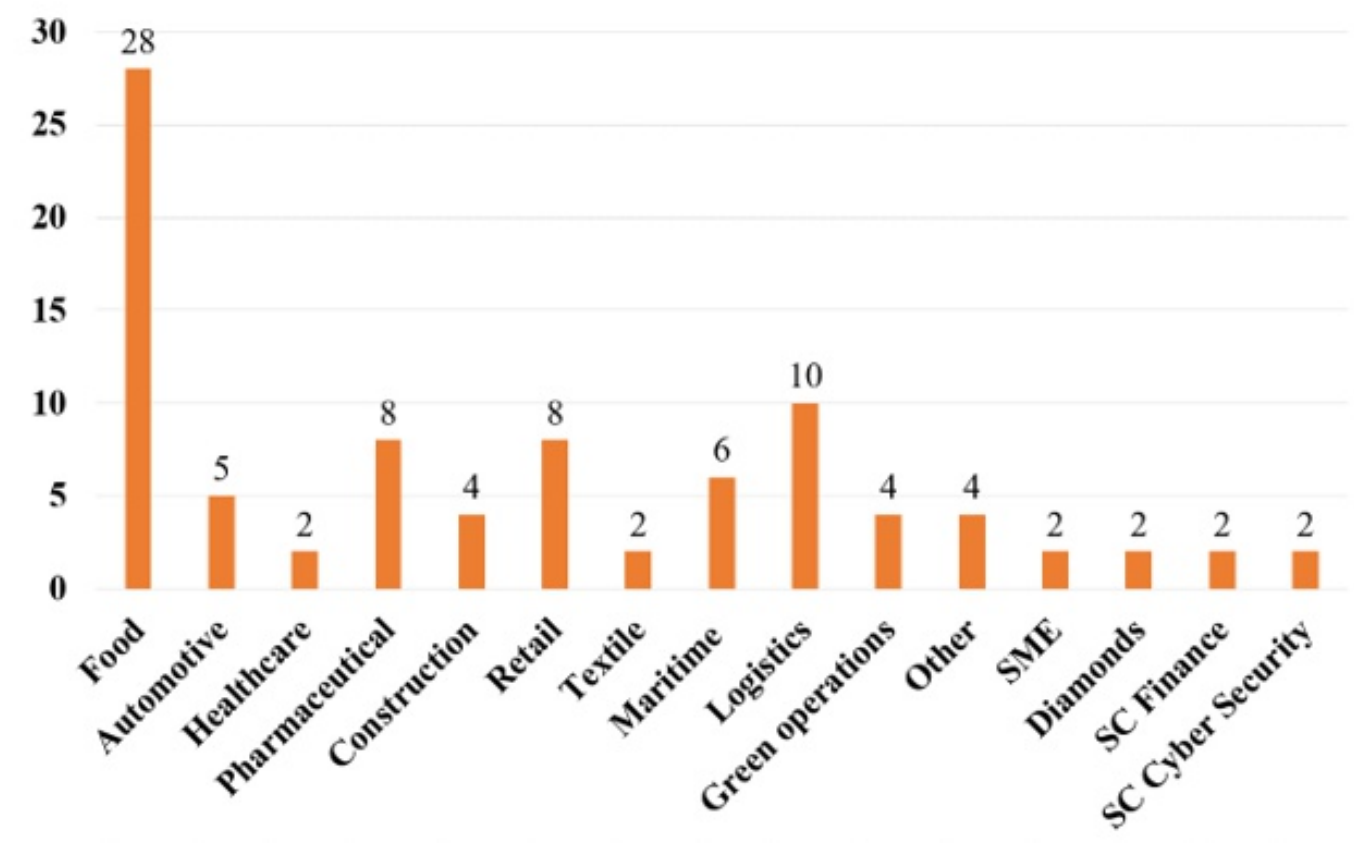

Figure 2. Leading sectors for case studies in the blockchain-supply chain field 


\section{Learning from Early Adopters of Blockchain Technology: A Systematic Review of Supply Chain Case Studies \\ Sevda Dede, Mesut Can Köseoğlu, H. Funda Yercan}

Finally, blockchain technology provides immutability, which prevents counterfeting of documents, and, thus, increasies trust between parties in the supply chain. "Smart contracts" enable more efficient business arrangements by generating automated documentation for use in a supply chain, which are among the most commonly mentioned advantages of blockchain implementation. If records in a supply chain could be immutable and eliminate counterfeting, this would ensure a high level of trust. With need for intermediaries removed, no single company then has control over the entire business process in an ecosystem, thus eliminating issues like disclosure and accountability, while being cost effective.

\subsection{What are the biggest challenges to adopting blockchain technology in supply chains?}

The most common challenge emphasized in the case studies is the uncertain regulatory environment. Uncertain and divergent laws and regulations negatively impact the efficiency and effectiveness of international trade applications, as organizations have the tendency of being reluctant to adopt blockchain without relevent national or international regulations. This may spread an unhelpful generalization of blockchain systems, causing small and medium enterprises, farmers, and other small scale members of the supply chain to avoid blockchain technology.

A second common challenge is scalability. Although data handling has come a long way and verification durations can be reduced substantially with blockchain accounting, due to complexity of data produced throughout supply chain processes, the amount of time spent data handling and verifying is still not yet acceptable for IoT environments, where timing is crucial. The case studies mention that available DLT systems can be used for small scale operations, whereas it is better with large scale operations for organizations to build their own blockchain system, though this generate additional costs for implementation.

Thirdly, a common challenge is the requirement to technologically and socially understand blockchain systems. With digitally driven global trade, blockchain implementations require considerable network size and speed. Hence, it constitutes a critical problem if only small parts of a supply chain have the required infrastructure, while the rest do not. Simply put, oldfashioned, conservative social mindsets along with lack of current technological understanding for blockchain implementation in supply chains, are challenges which must be faced. Another major challenge refers to one of the main features of blockchain systems, which is transparency. This research shows that complete transparency is not a desirable feature for blockchain implementation in certain sectors. Transperency issues primarily came up under data privacy concerns for pharmaceutical and food supply chains. If blockchain implementation is not successful, disruption in logistics processes creates difficulties with supply chain transparency and traceability. The option of deploying a private permissioned blockchain is an alternative when transparency is a main concern, though it will likely be costly. For implementations that provide their customers direct public access to the blockchain, privacy concerns are more likely to arise.

In addition to these concerns, the risk of cyber attacks appears to be another major challenge for blockchain implementation. Digitalization, while providing many benefits, also opens sectors to cyber crime. Though one of blockchain's main features is security provided by the distributed network structure, the relevant studies deem extra countermeasures necessary regarding cyber attacks.

Finally, adopting blockchain can be a great challenge in itself. While common standards for distributed ledger systems remain elusive, it is unrealistic to think of blockchain as a "one-size-fits-all" type of technology. It is difficult to create a supply chain where all parties, small and big, are users of a blockchain ledger, without a standardized environment, along with sound regulatory, technological, privacy, and scalability strategies. All these unsolved challenges have led people who use and operate supply chains to be reluctant to invest in blockchain technology, which, for certain sectors, is still considered risky.

\section{Conclusion}

Global supply chains are a key area for applying blockchain distributed ledger technology. The reasons why supply chains are a potentially high-gain area for blockchain implementation include its complex network structure comprising of multiple stakeholders, eliminating intermediaries and paperwork, and increasing transparency, traceability, and efficiency.

The earliest blockchain-supply chain case studies found in the WoS database are from 2018, while the majority of 


\section{Learning from Early Adopters of Blockchain Technology: A Systematic Review of Supply Chain Case Studies \\ Sevda Dede, Mesut Can Köseoğlu, H. Funda Yercan}

studies were published in 2020. While this small time window offers a perspective on trends in these case studies, it also limits the possible scope of the study.

Overall the case studies regarding blockchain implementation in supply chains are dominated by food supply chain cases. Most of the food supply chain case studies sought traceability, efficiency, and transparency enabled by blockchain, as a way to increase efficiency in the supply process while improving cost effectiveness. This tendency was mirrored in case studies of retail, pharmaceuticals, general logistic processes, automotive, maritime, construction, and green operations. In the case studies reviewed, the most commonly mentioned supply chain beneficial features of blockchain were traceability and transparency, while immutability and trust also displayed importantly in the literature.

Benefits of blockchain implementation in supply chains from the case studies mostly refer to the features of distributed ledger systems. The main benefits of using blockchain in supply chains include real time data handling with monitoring and controlling of data in a virtual environment, less paperwork, increased efficiency with faster response time, increased supply chain visibility, and reduced geographic limitations. Blockchains also gain advantage from flexibility, as data transparency provides data accessibility and information sharing among the participants of the ecosystem, increasing communication potential. Interoperability, which connects all network users in a secure environment, increases efficiency and transparency. The immutability feature of blockchain increases trust by preventing counterfeiting, while also eliminating intermediaries, increasing efficiency, improving supply chain operations, and helping achieve supply chain strategies.

Blockchain, however, comes with its own challenges, including the current uncertain regulatory environment, scalability complexities, adequate technological understanding and requirements, issues involving transparency and privacy, as well as cyber threats. Diverse laws and regulations prevent the efficiency of international trade applications, and cause reluctancy to adopt blockchain supply chain solutions. For data handling in small scale operations, available DLT systems can be used, while for large scale operations it is better for organizations to build their own blockchain system, although that generates additional implementation costs. Conservative decision-making processes can make it difficult for an organization to accept technological developments, thus diminishing the impact of blockchain features if not preventing the organization from adoption. Transperency issues have been mentioned involving data privacy concerns, with complete transparency not a desirable feature for blockchain implementations in certain sectors. With a lack of common standards, it is unrealistic to think of blockchain as a "one-size-fits-all" type of technology. Finally, while blockchain digitally speeds up supply chains, it also opens them to the threat of cyber attacks.

Our paper contributes to the literature by showcasing the use of blockchain in supply chains via multiple case studies, by learning from early adopters of blockchain technology in supply chain practices, and by providing information regarding the main expectations supply chain stakeholders bring when considering blockchain implementation for their processes. Though our aim in analyzing multiple case studies for this research was to enable a wider range of analysis and minimize researcher bias, the study still had a number of limitations. These include having analyzed the benefits and challenges captured from cases in specific supply chain domains in a way so as to provide only generalized results, as well as conducting the electronic search only in the Web of Science database.

To conclude, this study was essentially a review of case studies, revolving around a number of research questions that were asked of each case study. Therefore, our learning aim from early adopters was limited to the main trends in blockchain adoption and reasons for organizations to get involved. Building on this, further research should be conducted to understand what the various features of blockchain really mean for organizations and how they function in real life. Traceability, for example, could be a good topical starting point to focus on developing a further understanding of how global supply chains increase traceability using blockchain. An additional research paper might still review several cases, but this time looking at the details of each case for the predefined blockchain feature. A similar approach could be used to examine blockchain implementation in certain sectors. In this manner, focusing on how global food supply chains solve the problem of provenance through blockchain technology, or how global supply chains are increasing the efficiency of their operations through the use of blockchain, could help spread the knowledge gained at global-enterprise level to local players. Better 


\title{
Learning from Early Adopters of Blockchain Technology: A Systematic Review of Supply Chain Case Studies
}

\author{
Sevda Dede, Mesut Can Köseoğlu, H. Funda Yercan
}

understanding "how" blockchain technology contributes to solving certain business problems at this early stage might also require qualitative in-depth interviews.

\section{References}

Aich, S., Chakraborty, S., Sain, M., Lee, H.I., \& Kim, H.C. 2019. A Review on Benefits of IoT Integrated Blockchain based Supply Chain Management Implementations across Different Sectors with Case Study. In 2019 21st International Conference on Advanced Communication Technology (ICACT), 138141. IEEE.

DOI: https://doi.org/10.23919/icact.2019.8701910

Alles, M., \& Gray, G.L. 2020. “The First Mile Problem”: Deriving an endogenous demand for auditing in blockchain-based business processes. International Journal of Accounting Information Systems, 38, 100465.

DOI: https://doi.org/10.1016/j.accinf.2020.100465

Bal, M., \& Pawlicka, K. 2021. Supply Chain Finance and Challenges of Modern Supply Chains. Logforum, 17(1): 71-82.

DOI: https://doi.org/10.17270/j.log.2021.525

Baralla, G., Pinna, A., Tonelli, R., Marchesi, M., \& Ibba, S. 2021. Ensuring Transparency and Traceability of Food Local Products: A blockchain application to a smart tourism region. Concurrency and Computation: Practice and Experience, 33(1), e5857.

DOI: https://doi.org/10.1002/cpe.5857

Bodkhe, U., Tanwar, S., Bhattacharya, P., \& Kumar, N. 2020. Blockchain for Precision Irrigation: opportunities and challenges. Transactions on Emerging Telecommunications Technologies, e4059. DOI: https://doi.org/10.1002/ett.4059

Caldarelli, G., Rossignoli, C., \& Zardini, A. 2020. Overcoming the Blockchain Oracle Problem in the Traceability of Non-Fungible Products. Sustainability, 12(6), 2391.

DOI: https://doi.org/10.3390/su12062391

Calle, G., DiCaprio, A., Stassen, M., \& Manzer, A. 2019. Can Blockchain Futureproof Supply Chains? A Brexit case study. In Disruptive Innovation in Business and Finance in the Digital World. Emerald Publishing Limited.

Casado-Vara, R., Prieto, J., De la Prieta, F., \& Corchado, J.M. 2018. How Blockchain Improves the Supply Chain: case study alimentary supply chain. Procedia computer science, 134: 393-398.

DOI: https://doi.org/10.1016/j.procs.2018.07.193
Casino, F., Kanakaris, V., Dasaklis, T.K., Moschuris, S., Stachtiaris, S., Pagoni, M., \& Rachaniotis, N.P. 2020. Blockchain-based Food Supply Chain Traceability: a case study in the dairy sector. International Journal of Production Research, 1-13.

DOI: https://doi.org/10.1080/00207543.2020.1789238

Cui, Y., Idota, H., \& Ota, M. 2019. Improving Supply Chain Resilience with Implementation of New System Architecture. In 2019 IEEE Social Implications of Technology (SIT) and Information Management (SITIM) 1-6. IEEE.

DOI: https://doi.org/10.1109/sitim.2019.8910226

Curbera, F., Dias, D.M., Simonyan, V., Yoon, W.A., \& Casella, A. 2019. Blockchain: An enabler for healthcare and life sciences transformation. IBM Journal of Research and Development, 63(2/3): 8-1.

DOI: https://doi.org/10.1147/jrd.2019.2913622

Danese, P., Mocellin, R., \& Romano, P. 2021. Designing Blockchain Systems to Prevent Counterfeiting in Wine Supply Chains: a multiple-case study. International Journal of Operations \& Production Management, 41(13): 1-33.

DOI: https://doi.org/10.1108/ijopm-12-2019-0781

Di Ciccio, C., Cecconi, A., Mendling, J., Felix, D., Haas, D., Lilek, D., Riel, F; Rumpl, A \& Uhlig, P. 2018. Blockchain-based Traceability of Inter-Organisational Business Processes. In International Symposium on Business Modeling and Software Design, 56-68. Springer, Cham.

Duncan, S. 2020. Providers must Look to Blockchain to Fix the Lack of Supply Chain Transparency Exposed by COVID-19. HFS Research.

Ethirajan, M., Kandasamy, J., \& Kumaraguru, S. 2020. Connecting Engineering Technology with Enterprise Systems for Sustainable Supply Chain Management. Smart and Sustainable Manufacturing Systems, 4(1): 33-48.

DOI: https://doi.org/10.1520/SSMS20190037

Fu, H., Zhao, C., Cheng, C., \& Ma, M. 2020. Blockchainbased Agri-Food Supply Chain Management: case study in China. International Food and Agribusiness Management Review, 23(1030-2021-194): 667-679.

DOI: https://doi.org/10.22434/ifamr2019.0152

Garrard, R., \& Fielke, S. 2020. Blockchain for Trustworthy Provenances: A case study in the Australian aquaculture industry. Technology in Society, 62, 101298.

DOI: https://doi.org/10.1016/j.techsoc.2020.101298

Gausdal, A.H., Czachorowski, K.V., \& Solesvik, M.Z. 2018. Applying Blockchain Technology: evidence from Norwegian companies. Sustainability, 10(6): 1985. DOI: https://doi.org/10.3390/su10061985 


\section{Learning from Early Adopters of Blockchain Technology: A Systematic Review of Supply Chain Case Studies}

\section{Sevda Dede, Mesut Can Köseoğlu, H. Funda Yercan}

Grest, M., Lauras, M., Montarnal, A., Sarazin, A., \& Bousseau, G. 2019. A Meta Model for a Blockchainbased Supply Chain Traceability. In 2019 International Conference on Industrial Engineering and Systems Management (IESM), 1-6. IEEE.

DOI:

https://doi.org/10.1109/iesm45758.2019.8948159

Hafizon, M.I., Wicaksono, A., \& Farizan, F.N. 2019. E-Toll Laut: Blockchain port as the key for realizing indonesia's maritime fulcrum. In Proceedings of the 12th International Conference on Theory and Practice of Electronic Governance, 36-45.

DOI: https://doi.org/10.1145/3326365.3326371

Haroon, A., Basharat, M., Khattak, A.M., \& Ejaz, W. 2019. Internet of Things Platform for Transparency and Traceability of Food Supply Chain. In 2019 IEEE 10th Annual Information Technology, Electronics and Mobile Communication Conference (IEMCON), 13-19. IEEE.

DOI: https://doi.org/10.1109/iemcon.2019.8936158

Kanak, A., Ugur, N., \& Ergun, S. 2019. A Visionary Model on Blockchain-based Accountability for Secure and Collaborative Digital Twin Environments. In 2019 IEEE International Conference on Systems, Man and Cybernetics (SMC), 3512-3517. IEEE.

DOI: https://doi.org/10.1109/smc.2019.8914304

Khatoon, A., Verma, P., Southernwood, J., Massey, B., \& Corcoran, P. 2019. Blockchain in Energy Efficiency: Potential applications and benefits. Energies, 12(17), 3317.

DOI: https://doi.org/10.3390/en12173317

Kitchenham, B. 2004. Procedures for Performing Systematic Reviews. Keele, UK, Keele University, 33(2004): 1-26.

Koirala, R.C., Dahal, K., Matalonga, S., \& Rijal, R. 2019. A Supply Chain Model with Blockchain-enabled Reverse Auction Bidding Process for Transparency and Efficiency. In 2019 13th International Conference on Software, Knowledge, Information Management and Applications (SKIMA), 1-6. IEEE.

DOI:

https://doi.org/10.1109/skima47702.2019.8982476

Kshetri, N. 2018. Blockchain's Roles in Meeting Key Supply Chain Management Objectives. International Journal of Information Management, 39: 80-89.

DOI: https://doi.org/10.1016/b978-0-323-899345.00002-7

Kshetri, N. 2021. Blockchain and Supply Chain Management. Cambridge: Elsevier.

Kumar, A., Abhishek, K., Rukunuddin Ghalib, M., Nerurkar, P., Bhirud, S., Alnumay, W., Kumar, S.A., Chatterjee, P., \& Ghosh, U. 2020. Securing Logistics System and Supply Chain Using Blockchain. Applied Stochastic Models in Business and Industry, 37(3): 413428.

DOI: https://doi.org/10.1002/asmb.2592
Kumar, A., Abhishek, K., Nerurkar, P., Ghalib, M.R., Shankar, A., \& Cheng, X. 2020. Secure Smart Contracts for Cloud-Based Manufacturing Using Ethereum Blockchain. Transactions on Emerging Telecommunications Technologies, e4129.

DOI: https://doi.org/10.1002/ett.4129

Lam, O.W.A., \& Zhibin, L.E.I. 2019. Textile and Apparel Supply Chain with Distributed Ledger Technology (DLT). In 2019 20th IEEE International Conference on Mobile Data Management (MDM), 447-451. IEEE.

DOI: https://doi.org/10.1109/mdm.2019.000-4

Li, L., \& Zhou, H. 2020. A Survey of Blockchain with Applications in Maritime and Shipping Industry. Information Systems and e-Business Management, 119.

DOI: https://doi.org/10.1007/s10257-020-00480-6

Li, M., Shao, S., Ye, Q., Xu, G., \& Huang, G.Q. 2020. Blockchain-enabled Logistics Finance Execution Platform for Capital-constrained E-commerce Retail. Robotics and Computer-Integrated Manufacturing, 65: 101962.

DOI: https://doi.org/10.1016/j.rcim.2020.101962

Maersk Sustainability Report. 2021. A.P. Moller-Maersk A/S, Copenhagen, Denmark. Available Online: https://www.maersk.com/about/sustainability, accessed on 25 April 2021.

Maity, M., Tolooie, A., Sinha, A.K., \& Tiwari, M.K. 2021. Stochastic Batch Dispersion Model to Optimize Traceability and Enhance Transparency Using Blockchain. Computers \& Industrial Engineering, 154: 107134.

DOI: https://doi.org/10.1016/j.cie.2021.107134

Miehle, D., Henze, D., Seitz, A., Luckow, A., \& Bruegge, B. 2019. Partchain: A Decentralized Traceability Application for Multi-Tier Supply Chain Networks in the Automotive Industry. In 2019 IEEE International Conference on Decentralized Applications and Infrastructures (DAPPCON), 140-145. IEEE.

DOI: https://doi.org/10.1109/dappcon.2019.00027

Orjuela, K.G., Gaona-García, P.A., \& Marin, C.E.M. 2021. Towards an Agriculture Solution for Product Supply Chain Using Blockchain: case study Agro-chain with BigchainDB. Acta Agriculturae Scandinavica, Section $B$-Soil \& Plant Science, 71(1): 1-16.

DOI: https://doi.org/10.1080/09064710.2020.1840618

Park, A., \& Li, H. 2021. The Effect of Blockchain Technology on Supply Chain Sustainability Performances. Sustainability, 13(4), 1726.

DOI: https://doi.org/10.3390/su13041726

Patelli, N., \& Mandrioli, M. 2020. Blockchain Technology and Traceability in the Agrifood Industry. Journal of Food Science, 85(11): 3670-3678.

DOI: https://doi.org/10.1111/1750-3841.15477

Pérez, J.J.B., Queiruga-Dios, A., Gayoso Martínez, V., \& Martín del Rey, A. 2020. Traceability of Ready-to-wear Clothing Through Blockchain Technology. Sustainability, 12(18), 7491.

DOI: https://doi.org/10.3390/su12187491 


\section{Learning from Early Adopters of Blockchain Technology: A Systematic Review of Supply Chain Case Studies}

\section{Sevda Dede, Mesut Can Köseoğlu, H. Funda Yercan}

Philipp, R. 2020. Blockchain for LBG Maritime Energy Contracting and Value Chain Management: A green shipping business model for seaports. Environmental \& Climate Technologies, 24(2): 329-349.

DOI: https://doi.org/10.2478/rtuect-2020-0107

Philipp, R., Prause, G., \& Gerlitz, L. 2019. Blockchain and Smart Contracts for Entrepreneurial Collaboration in Maritime Supply Chains. Transport and Telecommunication, 20(4): 365-378.

DOI: https://doi.org/10.2478/ttj-2019-0030

Potancok, M; Ptackova, V; Cirkovsky, T. 2020. Blockchain Implementation into Supply Chain Management. In 2020 Digitalized Economy, Society and Information Management (IDIMT-2020), 305-314.

DOI:

https://doi.org/10.1109/logistiqua49782.2020.935387 9

Prause, G. 2019. Smart Contracts for Smart Supply Chains. IFAC-PapersOnLine, 52(13): 2501-2506.

DOI: https://doi.org/10.1016/j.ifacol.2019.11.582

Prause, G., \& Boevsky, I. 2019. Smart Contracts for Smart Rural Supply Chains. Bulgarian Journal of Agricultural Science, 25(3): 454-463.

DOI: https://doi.org/10.1016/j.ifacol.2019.11.582

Pundir, A.K., Jagannath, J.D., Chakraborty, M., \& Ganpathy, L. 2019. Technology Integration for Improved Performance: A case study in digitization of supply chain with integration of internet of things and blockchain technology. In 2019 IEEE 9th Annual Computing and Communication Workshop and Conference (CCWC), 170-176. IEEE.

DOI: https://doi.org/10.1109/ccwc.2019.8666484

PwC. 2020. Time for Trust: The trillion dollar reasons to rethink blockchain.

https://www.pwc.com/timefortrust

Rijanto, A. 2020. Business Financing and Blockchain Technology Adoption in Agroindustry. Journal of Science and Technology Policy Management.

DOI: https://doi.org/10.1108/jstpm-03-2020-0065

Rodríguez-Espíndola, O., Chowdhury, S., Beltagui, A., \& Albores, P. 2020. The Potential of Emergent Disruptive Technologies for Humanitarian Supply Chains: the integration of blockchain, Artificial Intelligence and $3 \mathrm{D}$ printing. International Journal of Production Research, 58(15): 4610-4630.

DOI: https://doi.org/10.1080/00207543.2020.1761565

Roeck, D., Sternberg, H., \& Hofmann, E. 2020. Distributed Ledger Technology in Supply Chains: a transaction cost perspective. International Journal of Production Research, 58(7): 2124-2141.

DOI: https://doi.org/10.1080/00207543.2019.1657247

Rogerson, M., \& Parry, G.C. 2020. Blockchain: case studies in food supply chain visibility. Supply Chain Management: An International Journal, 25(5): 601614.

DOI: https://doi.org/10.1108/scm-08-2019-0300
Scheid, E., Rodrigues, B., \& Stiller, B. 2019. Toward a Policy-based Blockchain Agnostic Framework. In 2019 IFIP/IEEE Symposium on Integrated Network and Service Management (IM), 609-613. IEEE.

Shemov, G., de Soto, B.G., \& Alkhzaimi, H. 2020. Blockchain Applied to the Construction Supply Chain: A case study with threat model. Frontiers of Engineering Management, 7(4): 564-577.

DOI: https://doi.org/10.1007/s42524-020-0129-x

Sivula, A., Shamsuzzoha, A., \& Helo, P. 2021. Requirements for Blockchain Technology in Supply Chain Management: An exploratory case study. Operations and Supply Chain Management-An International Journal, 14(1): 39-50.

DOI: https://doi.org/10.31387/oscm0440284

Sternberg, H.S., Hofmann, E., \& Roeck, D. 2021. The Struggle is Real: insights from a supply chain blockchain case. Journal of Business Logistics, 42(1): 71-87.

DOI: https://doi.org/10.1111/jbl.12240

Stopford, M. 2009. Maritime Economics. Routledge. New York, USA.

Stranieri, S., Riccardi, F., Meuwissen, M.P., \& Soregaroli, C. 2021. Exploring the Impact of Blockchain on the Performance of Agri-food Supply Chains. Food Control, 119, 107495.

DOI: https://doi.org/10.1016/j.foodcont.2020.107495

Sund, T., Lööf, C., Nadjm-Tehrani, S., \& Asplund, M. 2020. Blockchain-based Event Processing in Supply Chains-A case study at IKEA. Robotics and ComputerIntegrated Manufacturing, 65, 101971.

DOI: https://doi.org/10.1016/j.rcim.2020.101971

Tan, W.K.A., \& Sundarakani, B. 2020. Assessing Blockchain Technology Application for Freight Booking Business: A case study from technology acceptance model perspective. Journal of Global Operations and Strategic Sourcing, 14(1): 202-223. DOI: https://doi.org/10.1108/jgoss-04-2020-0018

Tönnissen, S., \& Teuteberg, F. 2020. Analysing the Impact of Blockchain-technology for Operations and Supply Chain Management: An explanatory model drawn from multiple case studies. International Journal of Information Management, 52, 101953.

DOI: https://doi.org/10.1016/j.ijinfomgt.2019.05.009

Tseng, C.T., \& Shang, S.S. 2021. Exploring the Sustainability of the Intermediary Role in Blockchain. Sustainability, 13(4), 1936.

DOI: https://doi.org/10.3390/su13041936

van Hoek, R. 2019. Developing a Framework for Considering Blockchain Pilots in the Supply chainlessons from early industry adopters. Supply Chain Management: An International Journal, 25: 115-121 DOI: https://doi.org/10.1108/scm-05-2019-0206

Vishnubhotla, A.K., Pati, R.K., \& Padhi, S.S. 2020. Can Projects on Blockchain Reduce Risks in Supply Chain Management?: An oil company case study. IIM Kozhikode Society \& Management Review, 9(2): 189- 


\section{Learning from Early Adopters of Blockchain Technology: A Systematic Review of Supply Chain Case Studies}

\section{Sevda Dede, Mesut Can Köseoğlu, H. Funda Yercan}

201.

DOI: https://doi.org/10.1177/2277975220913370

Vivaldini, M. 2021. Blockchain in Operations for Food Service Distribution: steps before implementation. International Journal of Logistics Management.

DOI: https://doi.org/10.1108/ijlm-07-2020-0299

Wamba, F.S., Kamdjoug, J.R.K., Epie Bawack, R., \& Keogh, J.G. 2020. Bitcoin, Blockchain and Fintech: A systematic review and case studies in the supply chain. Production Planning \& Control, 31(2-3): 115142.

DOI: https://doi.org/10.1080/09537287.2019.1631460

Wang, Y., Chen, C.H., \& Zghari-Sales, A. 2020. Designing a Blockchain Enabled Supply Chain. International Journal of Production Research, 59(5): 1450-1475.

DOI: https://doi.org/10.1080/00207543.2020.1824086

Wang, Z., Wang, T., Hu, H., Gong, J., Ren, X., \& Xiao, Q. 2020. Blockchain-based Framework for Improving Supply Chain Traceability and Information Sharing in Precast Construction. Automation in Construction, 111, 103063.

DOI: https://doi.org/10.1016/j.autcon.2019.103063

White, M. 2019. Shipping in the Age of Blockchain. https://www.youtube.com/watch? $\mathrm{v}=$ Xwqo_fwPEJo

Wu, H., Cao, J., Yang, Y., Tung, C.L., Jiang, S., Tang, B., Liu, Y; Wang, X.Q., \& Deng, Y. 2019. Data Management in Supply Chain Using Blockchain: Challenges and a case study. In 2019 28th International Conference on Computer Communication and Networks (ICCCN), 1-8. IEEE. DOI: https://doi.org/10.1109/icccn.2019.8846964

Yusuf, H., Surjandari, I., \& Rus, A.M.M. 2019. Multiple Channel with Crash Fault Tolerant Consensus Blockchain Network: a case study of vegetables supplier supply chain. In 2019 16th International Conference on Service Systems and Service Management (ICSSSM), 1-4. IEEE.

DOI: https://doi.org/10.1109/icsssm.2019.8887678

Zhou, Y., Soh, Y.S., Loh, H.S., \& Yuen, K.F. 2020. The Key Challenges and Critical Success Factors of Blockchain Implementation: Policy implications for Singapore's maritime industry. Marine Policy, 122, 104265.

DOI: https://doi.org/10.1016/j.marpol.2020.104265

Citation: Dede, S., Mesut Can Köseoğlu, M.C., Yercan, H.F. 2021. Learning from Early Adopters of Blockchain Technology: A Systematic Review of Supply Chain Case Studies. Technology Innovation Management Review, 11(6): 19-31. http://doi.org/10.22215/timreview/1447

Keywords: Blockchain, Distributed ledger technology, Supply chain, Systematic review, Digitalization

\section{About the Authors}

Sevda Dede is a $\mathrm{PhD}$ candidate at Istanbul University and is working on her dissertation on the orchestration of digital innovation in business ecosystems. She holds BA and MA degrees in Logistics Management, both from Izmir University of Economics. She began her career as a research assistant in 2009 and worked as a professional in business development and supply chain management departments until 2016. She is currently a full-time lecturer at Piri Reis University, in her fourth year of teaching experience. In her research, she mainly focuses on digital innovation in supply chains and business ecosystems from a managerial point of view.

M. Can Köseoğlu graduated from Piri Reis University Maritime Transportation and Management Engineering in 2016 and obtained his MSc degree in Maritime Transportation Engineering from Istanbul Technical University, while also working towards his second MSc degree in Industrial Engineering in Galatasaray University. Currently he is working as a research assistant in Piri Reis University Maritime Transportation and Management Engineering Department. His studies focus on green ports, ship routing optimization and smart technologies in maritime transportation.

Funda Yercan, a Professor of International Shipping and Logistics Management since 2005, holds a PhD in International Shipping, Transportation and Logistics from the University of Plymouth in the UK. She has been in professional life and academia more than 30 years, teaching at undergraduate and graduate levels, conducting research, publishing papers in international journals indexed in SSCI and SCI, presenting papers at international conferences in a number of countries, and serving as an administrator. She was also a Visiting Professor at Maine Maritime Academy-MMA in the USA, founding Dean of the Maritime Faculty at Kyrenia American University in Northern Cyprus and is currently the Dean of the Maritime Faculty at Piri Reis University in Istanbul, Turkey. Her studies focus on international shipping, maritime logistics, supply chains, and smart technologies. 